\title{
Seismicity and the Geopotential Stress Field of the Continental Lithosphere
}

\author{
$\underline{\text { Randell Stephenson }}^{1}$, Christian Schiffer ${ }^{2}$, Søren Bom Nielsen ${ }^{3}$ \\ ${ }^{1}$ University of Aberdeen, AB24 3UE, Aberdeen, Scotland \\ ${ }^{2}$ Uppsala University, 75237, Uppsala, Sweden \\ ${ }^{3}$ Aarhus University, 8000, Aarhus, Denmark
}

doi: https://doi.org/10.21467/abstracts.93.50

\begin{abstract}
ABSTRA CT
A range of stress sources contribute to the stress state of the lithosphere (e.g. Ranalli, 1995): slab pull, shear resistance at subduction zones and strike slip faults, convection drag at the base of the lithosphere, stresses transferred to the interior of plates from plate boundary processes, horizontal gradients of pressure variations at the base of the lithosphere ("dynamic topography") and horizontal gradients of lithospheric potential energy. The last, which we will refer to as the "geopotential energy" or GPE-sourced stress field, incorporates the lateral variability of lithosphere thickness and temperature (density), crustal thickness and surface topography (basins and mountains, mid ocean ridges). We have calculated a model of the GPE stress field of part of the Earth's northern hemisphere that includes most of North America, the north Atlantic realm and Europe as far east as central Asia and compared the predicted principal horizontal stress directions to observed values from the Global Stress Map (GSM; Heidbach et al., 2018), where available, spatially averaged and interpolated as well as to seismicity since 1973. In large parts of the intraplate domains of continental lithosphere in our study area the computed GPE stress directions closely align with the observed GSM stress directions. However, the GPE and GSM stress directions are largely incompatible in zones where the bulk of present-day seismicity occurs (cf. Nielsen et al., 2014). This suggests that GPE stresses are overprinted in some parts of the lithosphere, particularly (and not surprisingly) in regions very close to active plate boundaries. We are investigating this relationship between GPE stresses and seismicity further, asking whether such a relationship, placed in a quantitative framework including the spatial and depth distribution of relevant earthquakes, the record of released seismic energy, and of local lithospheric structure is robust enough to provide added value to hazard assessments. A secondary aim that we have is to try to determine whether non-GPE stresses are required in areas of present-day observed intraplate seismicity or whether perturbations to the GPE stress field caused by local, thermo-structural effects in the intraplate lithosphere are sufficient (cf. Stephenson et al., in review).
\end{abstract}

\section{References}

Heidbach, O., M. Rajabi, X. Cui, K. Fuchs, B. Müller, J. Reinecker, K. Reiter, M. Tingay, F. Wenzel, F. Xie, M.O. Ziegler, M.-L. Zoback and M.D. Zoback, 2018. The World Stress Map database release 2016: Crustal stress pattern across scales. Tectonophysics, 744, 484-498, doi:10.1016/j.tecto.2018.07.007

Nielsen, S.B., Stephenson, R., Schiffer, C., 2014. Deep controls on intraplate basin inversion, in: Talwani, P. (Ed.), Intraplate Earthquakes. Cambridge University Press.

Ranalli, G., 1995. Rheology of the Earth. Chapman and Hall in London, New York.

Stephenson, R., Schiffer, C., Peace, A., Nielsen. S.B. and Jess, S., in review. Late Cretaceous-Cenozoic basin inversion and paleo-stress fields in the North Atlantic-western Alpine-Tethys realm: implications for intraplate tectonics. Earth-Science Reviews.

(C) 2020 Copyright held by the author(s). Published by AIJR Publisher in "Abstracts of The Second Eurasian RISK-2020 Conference and Symposium" April 12- 19, 2020, Tbilisi, Georgia. Jointly organized by AMIR Technical Services LLC, Georgian Technical University, Institute of Geography (Kazakhstan) and Russian Institute of Petroleum Geology and Geophysics.

AijR DOI: $10.21467 /$ abstracts. 93 